\title{
Ventilation/perfusion lung scan in pulmonary veno-occlusive disease
}

\author{
Andrei Seferian*,\#, , Badia Helal ${ }^{+}$, Xavier Jaïs*,\#,๘ Barbara Girerd*,\#, \\ Laura C. Price $^{\S}$, Sven Günther*,\#, , Laurent Savale*,\#, , Peter Dorfmüller ${ }^{\star}$, \\ Florence Parent*,\#, , Olivier Sitbon*,\#,ף, Marc Humbert*,\#,ף, \\ Gérald Simonneau*,\#, and David Montani*,\#,ף
}

ABSTRACT: Pulmonary veno-occlusive disease (PVOD), a rare form of pulmonary arterial hypertension (PAH), requires histological proof for definitive diagnosis; however, lung biopsy is not recommended in PAH. Recent conjoint European Respiratory Society/European Society of Cardiology guidelines suggest that nonmatched perfusion defects on ventilation/perfusion $\left(V^{\prime} / Q^{\prime}\right)$ lung scanning in PAH patients may suggest PVOD. The aim of our study was to evaluate $V^{\prime} / Q^{\prime}$ lung scans in a large cohort of PVOD and idiopathic or heritable PAH patients.

$V^{\prime} / Q^{\prime}$ lung scans from 70 patients with idiopathic or heritable $\mathrm{PAH}$ and 56 patients with confirmed or highly probable PVOD were reviewed in a double-blind manner.

The vast majority of $V^{\prime} / Q^{\prime}$ lung scans were normal or without significant abnormalities in both groups. No differences in ventilation or perfusion lung scans were observed between $\mathrm{PAH}$ and PVOD patients (all $\mathrm{p}>\mathbf{0 . 0 5}$ ). Furthermore, no differences were observed between confirmed $(n=31)$ or highly probable PVOD $(n=25)$. Nonmatched perfusion defects were found in seven (10\%) idiopathic PAH patients and four (7.1\%) PVOD patients $(p>0.05)$.

Nonmatched perfusion defects were rarely seen in a large cohort of idiopathic or heritable PAH and PVOD patients. Future recommendations should be amended according to these results suggesting that $V^{\prime} / Q^{\prime}$ lung scanning is not useful in discriminating PVOD from idiopathic PAH.

KEYWORDS: Guidelines, pulmonary arterial hypertension, pulmonary veno-occlusive disease, ventilation/perfusion lung scan

$\mathbf{P}$ ulmonary arterial hypertension $(\mathrm{PAH})$ is a severe condition characterised by vascular cell proliferation and remodelling of small pulmonary arteries that causes elevated pulmonary vascular resistance, leading to right heart failure and death [1-3]. The most recent clinical classification, proposed during the fourth World Symposium on Pulmonary Hypertension, divides pulmonary hypertension into five different groups, PAH being the first subgroup, which includes idiopathic and heritable $\mathrm{PAH}$, drug- and toxin-induced $\mathrm{PAH}$, and $\mathrm{PAH}$ associated with coexisting conditions (connective tissue disease, HIV infection, portal hypertension, congenital heart disease, schistosomiasis and chronic haemolytic anaemia) $[2,4,5]$. One of the prominent changes of the recent guidelines was to move pulmonary veno-occlusive disease (PVOD) and pulmonary capillary haemangiomatosis from separate categories into a single subcategory of PAH (group 1') [2]. PVOD is a rare form of PAH that remains poorly understood and is both difficult to diagnose and treat [6-11]. PVOD shares many similarities with idiopathic $\mathrm{PAH}$, in particular, clinical features and haemodynamic characteristics, and therefore it can be difficult to distinguish PVOD from idiopathic PAH [8]. PVOD patients exposed to $\mathrm{PAH}$-specific treatments may develop abrupt and potentially life-threatening deterioration due to severe pulmonary oedema $[8,12,13]$.

A definitive diagnosis of PVOD requires histological examination of lung samples showing extensive and diffuse occlusion of pulmonary veins by fibrous tissue and intimal thickening involving preferentially venules and small veins in lobular septa [10, 14]. However, lung biopsy for histolodure and therefore it is not recommended [11] We have recently demonstrated that a noninvasive approach, including suggestive findings on gical confirmation of PVOD is a high-risk proce-

\section{AFFILIATIONS}

*Université Paris-Sud, Faculté de Médecine, and

${ }^{\#}$ AP-HP, Centre de Référence de I'Hypertension Pulmonaire Sévère, Service de Pneumologie et Réanimation Respiratoire, DHU Thorax Innovation, Hôpital de Bicêtre Le Kremlin-Bicêtre,

+Service de Médecine Nucléaire, Hôpital Antoine Béclère, Clamart, "INSERM U999, Hypertension Artérielle Pulmonaire, and Physiopathologie et Innovation Thérapeutique, LabEx LERMIT, ${ }^{f}$ Service d'Anatomie Pathologique, Centre Chirurgical Marie Lannelongue, Le Plessis Robinson France.

${ }^{\S}$ Dept of Pulmonary Hypertension, Royal Brompton Hospital, London, UK.

CORRESPONDENCE

D. Montani

Centre de Référence de

I'Hypertension Pulmonaire Sévère, Service de Pneumologie, Hôpital de Bicêtre, Assistance Publique, Hôpitaux de Paris Université Paris-Sud 78 rue du Général Leclerc 94270 Le Kremlin-Bicêtre France E-mail: david.montani@bct.aphp.fr

Received:

June 072011

Accepted after revision: Nov 072011 First published online: Nov 162011 
high-resolution computed tomography (HRCT) of the chest, diffusing capacity of the lung for carbon monoxide $(D \mathrm{~L}, \mathrm{CO})$ and bronchoalveolar lavage, can be helpful to screen for PVOD patients $[8,15,16]$.

In recent conjoint European Respiratory Society (ERS)/ European Society of Cardiology (ESC) guidelines for diagnosis and treatment of pulmonary hypertension [4, 5], it has been suggested that nonmatched perfusion defects may also suggest the diagnosis of PVOD. However, this statement is based on few isolated reports of PVOD patients with a "high-probability ventilation/perfusion $\left(V^{\prime} / Q^{\prime}\right)$ lung scan" with multiple segmental perfusion defects in perfusion lung scan, mimicking proximal chronic thromboembolic pulmonary hypertension (CTEPH) [17].

The aim of this study was to evaluate the frequency of abnormalities in ventilation and perfusion lung scans, and the potential interest of this investigation as a noninvasive approach to differentiate PVOD from idiopathic or heritable PAH.

\section{METHODS}

\section{Subjects}

We retrospectively reviewed 56 consecutive $V^{\prime} / Q^{\prime}$ lung scans at the time of diagnosis for patients with confirmed $(n=31)$ or highly probable $(n=25)$ PVOD, referred to the French Reference Centre for Pulmonary Hypertension (Université Paris Sud 11, Hôpital Antoine Béclère, Paris, France) between 2000 and 2009 (PVOD group). The diagnosis of PVOD was considered "highly probable" if patients fulfilled the following characteristics: pre-capillary pulmonary hypertension, presence of two or more radiological abnormalities on HRCT of the chest (including lymph node enlargement, centrilobular ground-glass opacities and septal lines), low DL,CO or occult alveolar haemorrhage. Diagnosis of PVOD was considered as confirmed PVOD when histological proof of veno-occlusive disease was available or when patients with signs of "highly probable" disease developed pulmonary oedema after initiation of specific PAH therapy. Histological proof of veno-occlusive disease was based on haematoxylineosin-safran staining of biopsies $(n=1)$, post mortem $(n=1)$ or lungs obtained after lung transplantation $(n=10)$. The pathological hallmark of PVOD was defined as an extensive and diffuse obstruction of pulmonary veins and venules by intimal fibrosis, cellular proliferation and muscularisation $[10,18-20]$. As a control group, we reviewed 70 consecutive $V^{\prime} / Q^{\prime}$ lung scans performed at time of diagnosis in patients with idiopathic or heritable $\mathrm{PAH}$ (PAH group) diagnosed between 2007 and 2009.

Patients with drug- or toxin-induced $\mathrm{PAH}$ or $\mathrm{PAH}$ associated with other medical conditions were not included in the study. After obtaining written informed consent, point mutations and large rearrangements of the bone morphogenetic protein receptor II (BMPR2) gene were analysed in 72 patients (38 PAH patients and 34 PVOD patients) as described previously [20].

\section{Haemodynamic measurements}

Pre-capillary pulmonary hypertension was defined as mean pulmonary artery pressure $(\mathrm{mPpa}) \geqslant 25 \mathrm{mmHg}$ with a normal pulmonary capillary wedge pressure $(P \mathrm{pcw})(\leqslant 15 \mathrm{mmHg})$. $\mathrm{m} P$ pa, $P$ pcw, right atrial pressure and mixed venous oxygen saturation $\left(\mathrm{S}_{\mathrm{v}}, \mathrm{O}_{2}\right)$ were recorded. Cardiac output $(\mathrm{CO})$ was measured by the standard thermodilution technique. The cardiac index was calculated as the $\mathrm{CO}$ divided by the body surface area and systolic index as the cardiac index divided by heart rate. Pulmonary vascular resistance (PVR) was calculated as $(\mathrm{mPpa}-\mathrm{Ppcw}) / \mathrm{CO}$ and was expressed in Wood units. Baseline haemodynamic data and response to acute vasodilator testing with inhaled nitric oxide were performed for all subjects. A nitric oxide challenge (10 ppm for 5-10 min) was used and a positive acute response was defined as a reduction of $\mathrm{mP}$ pa of $>10 \mathrm{mmHg}$ to reach an absolute value of $\mathrm{mP}$ pa $<40 \mathrm{mmHg}$ and an increased or unchanged $\mathrm{CO}[3,21]$.

\section{Clinical and functional assessment}

Routine evaluation at baseline included medical history and physical examination. Age and clinical status assessed by modified New York Heart Association functional class (NYHA FC) were recorded at diagnosis [3]. A nonencouraged 6-min walk test was performed according to the American Thoracic Society recommendations [22] and the 6-min walk distance (6MWD) was recorded. Pulmonary function tests were also performed, including $D \mathrm{~L}, \mathrm{CO}$ assessment.

\section{$\mathbf{V}^{\prime} / \mathbf{Q}^{\prime}$ lung scan}

Ventilation imaging was carried out with ${ }^{99 \mathrm{~m}} \mathrm{Tc}$ Technegas (Cyclomedica Europe, Dublin, Ireland) followed by perfusion imaging using $180 \mathrm{MBq}{ }^{99 \mathrm{~m}}$ Tc-labelled human albumin macroaggregates. Six or eight views were taken using a highresolution parallel-hole collimator and were reviewed double blind. Quantitative $V^{\prime} / Q^{\prime}$ lung scanning was not considered necessary. The examinations were characterised as normal, with nonsystematised defects or with segmental/subsegmental defects in ventilation and perfusion. Segmental defects were defined as the presence of abnormalities in ventilation or perfusion for $>75 \%$ of a pulmonary segment. Subsegmental defects were defined as the presence of abnormalities in ventilation or perfusion for $25-75 \%$ of a pulmonary segment, while nonsystematised defects on the examination meant $<25 \%$ abnormalities.

\section{Statistical analysis}

Statistical analysis was performed using StatView version 5.0 (Abacus Concepts Inc., Berkley, CA, USA). Data are presented as mean $\pm \mathrm{SD}$, unless stated otherwise. Comparisons between PVOD and PAH patients were assessed by unpaired t-tests and Z-tests for comparing proportions. A p-value $<0.05$ was considered statistically significant and the $\mathrm{z}$-value was calculated for a $95 \%$ confidence interval.

\section{RESULTS}

\section{Characteristics of PVOD and PAH patients at diagnosis}

Demographic, clinical, haemodynamic and functional characteristics of PVOD $(n=56)$ and PAH patients $(n=70)$ at diagnosis are shown in table 1 . PVOD was confirmed in 31 (55\%) patients (histological confirmation in 12 patients) and was considered highly probable in $25(45 \%)$ patients. Age at diagnosis was broadly similar in PVOD and PAH patients (mean \pm SD $50.2 \pm 18.4$ versus $53.9 \pm 18.9$ yrs, respectively; $\mathrm{p}=0.13)$. Sex ratio was significantly different, with a female/ male ratio of 0.5 in the PVOD group and 1.6 in the PAH group 
$(\mathrm{p}<0.01) .43(76 \%)$ PVOD patients and $56(80 \%)$ PAH patients were in NYHA FC III, while $12(21.2 \%)$ PVOD and three $(4.3 \%)$ PAH were in NYHA FC class IV $(p=0.003)$. 6MWD was significantly lower in PVOD patients compared with $\mathrm{PAH}$ patients $(241 \pm 172$ versus $299 \pm 163 \mathrm{~m} ; \mathrm{p}=0.02)$. Regarding haemodynamic parameters, no significant differences were observed in $\mathrm{mPpa}, \mathrm{Ppcw}_{\mathrm{p}}, \mathrm{PVR}$ and $\mathrm{S}_{\mathrm{v}}, \mathrm{O}_{2}$ between PVOD and $\mathrm{PAH}$ patients (all $\mathrm{p}>0.05)$, except for cardiac index $(2.3 \pm 0.6$ versus $2.6 \pm 0.9 \mathrm{~L} \cdot \mathrm{min}^{-1} \cdot \mathrm{m}^{-2}$, respectively; $\mathrm{p}=0.01$ ) (online supplementary table). DL,CO was significantly lower in PVOD patients as compared to idiopathic PAH patients $(31.3 \pm 18.9$ and $\left.61.7 \pm 21.3 \mathrm{mmHg} \cdot \mathrm{L}^{-1} \cdot \mathrm{min}^{-1} ; \mathrm{p}<0.001\right)$. BMPR2 mutations were found in three out of the $38 \mathrm{PAH}$ patients tested and none of the 34 PVOD patients tested.

\section{Analysis of the $\mathrm{V}^{\prime} / \mathrm{Q}^{\prime}$ lung scans in PVOD and idiopathic PAH patients}

Data for perfusion and ventilation from $V^{\prime} / Q^{\prime}$ lung scans in PVOD and PAH patients are shown in figure 1. Normal perfusion was observed in 51 (72.9\%) PVOD patients and 46 $(82.1 \%)$ PAH patients $(p=0.3)$. Segmental or subsegmental defects were observed in four $(7.1 \%)$ PVOD patients and five $(7.1 \%)$ PAH patients $(\mathrm{p}=0.72)$. Nonsystematised defects were observed in the same proportion in both groups $(20 \%$ and $10.7 \%$, respectively; $\mathrm{p}=0.24$ ).

\begin{tabular}{|c|c|c|c|c|}
\hline \multirow[t]{2}{*}{ TABLE 1} & \multicolumn{4}{|c|}{$\begin{array}{l}\text { Demographic, clinical, haemodynamic, } \\
\text { functional characteristics and BMPR2 status at } \\
\text { diagnosis of pulmonary veno-occlusive disease } \\
\text { (PVOD) and pulmonary artery hypertension } \\
\text { (PAH) patients }\end{array}$} \\
\hline & & PVOD & PAH & $p$-value \\
\hline \multicolumn{2}{|l|}{ Patients n } & 56 & 70 & \\
\hline \multicolumn{2}{|c|}{ Age at diagnosis yrs } & $50 \pm 18$ & $54 \pm 18$ & 0.13 \\
\hline \multicolumn{2}{|c|}{ Female/male n (ratio) } & $19 / 37(0.5)$ & $43 / 27(1.6)$ & 0.003 \\
\hline \multicolumn{5}{|c|}{ NYHA FC } \\
\hline \multicolumn{2}{|l|}{$\|$} & $2(3.5)$ & $11(15.7)$ & \\
\hline \multicolumn{2}{|l|}{ III } & $43(76.7)$ & $56(80)$ & 0.003 \\
\hline \multicolumn{2}{|l|}{ IV } & $11(19.8)$ & $3(4.3)$ & \\
\hline \multicolumn{2}{|l|}{ 6MWD m } & $240 \pm 173$ & $299 \pm 163$ & 0.02 \\
\hline \multicolumn{2}{|l|}{$\mathrm{mPpa} \mathrm{mmHg}$} & $53 \pm 12$ & $53 \pm 15$ & 0.46 \\
\hline \multicolumn{2}{|l|}{ Ppcw mmHg } & $9 \pm 4$ & $8 \pm 4$ & 0.14 \\
\hline \multicolumn{2}{|l|}{$\mathrm{CO} L \cdot \mathrm{min}^{-1}$} & $3.97 \pm 1.4$ & $4.57 \pm 1.7$ & 0.01 \\
\hline \multicolumn{2}{|c|}{$\mathrm{CI} \mathrm{L} \cdot \mathrm{min}^{-1} \cdot \mathrm{m}^{-2}$} & $2.34 \pm 0.6$ & $2.63 \pm 0.9$ & 0.01 \\
\hline \multicolumn{2}{|c|}{ PVR $\mathrm{mmHg} \cdot \mathrm{L}^{-1} \cdot \mathrm{min}^{-1}$} & $12.6 \pm 8$ & $11.7 \pm 8$ & 0.25 \\
\hline \multicolumn{2}{|c|}{$\mathrm{Sv}, \mathrm{O} 2 \%$} & $61 \pm 10$ & $61 \pm 10$ & 0.33 \\
\hline \multicolumn{2}{|c|}{$D$ L,Co \% pred } & $31.3 \pm 18.9$ & $61.7 \pm 21.3$ & $<0.001$ \\
\hline \multicolumn{2}{|c|}{ BMPR2 status $n / N$ \% } & 0/34 (0) & 3/38 (8) & 0.27 \\
\hline \multicolumn{5}{|c|}{$\begin{array}{l}\text { Data are presented as mean } \pm \text { SD or } \mathrm{n}(\%) \text {, unless otherwise stated. BMPR2: } \\
\text { bone morphogenetic protein receptor II; NYHA FC: New York Heart Association } \\
\text { functional class; } 6 \mathrm{MWD} \text { : } 6 \text {-min walk distance; mPpa: mean pulmonary artery } \\
\text { pressure; Ppcw: pulmonary capillary wedge pressure; CO: cardiac output; Cl: } \\
\text { cardiac index; PVR: pulmonary vascular resistance; } \mathrm{Sv}_{\mathrm{O}} \mathrm{O}_{2} \text { : mixed venous } \\
\text { oxygen saturation; } \mathrm{DL}, \mathrm{CO} \text { : diffusing capacity of the lung for carbon monoxide; \% } \\
\text { pred: \% predicted. }\end{array}$} \\
\hline
\end{tabular}

In ventilation, no statistically relevant difference was observed between PAH and PVOD patients: normal ventilation (59 $(84.3 \%)$ versus $48(85.7 \%)$ patients; $\mathrm{p}=0.97)$; nonsystematised defects $(10(14.3 \%)$ versus seven $(12.5 \%) ; \mathrm{p}=0.97)$; segmental or subsegmental defects (one $(1.4 \%)$ versus one $(1.7 \%) ; \mathrm{p}=0.58)$.

\section{Analysis of patients with nonmatched perfusion defects}

In the 126 patients included in this study, 11 (8.7\%) patients had nonmatched perfusion defects, including seven $(10 \%)$ $\mathrm{PAH}$ and four $(7.1 \%)$ PVOD patients (three confirmed disease and one highly probable). Individual data for these 11 patients are presented in table 2 . The clinical history of the 11 patients with nonmatched perfusion defects was analysed in detail in order to find explanations for the $V^{\prime} / Q^{\prime}$ lung scan results. Two $\mathrm{PAH}$ patients had a previous history of acute pulmonary embolism with a delay between diagnosis of PAH/PVOD and pulmonary embolism of 26 and 60 months, respectively, associated in one patient with deep vein thrombosis and, therefore, prior use of anticoagulant therapy. One PAH patient had a history of superficial vein thrombosis with a 3-month period of anticoagulation therapy. In eight patients, no clinical history of thromboembolic disease was found.

The epidemiological, clinical, functional and haemodynamic characteristics of the 11 patients with nonmatched perfusion defects at the time of diagnosis were compared with those having matched or no perfusion defects $(n=115)$ (table 3). NYHA FC, 6MWD, haemodynamic characteristics and DL,CO measurements were similar in both groups, except for a
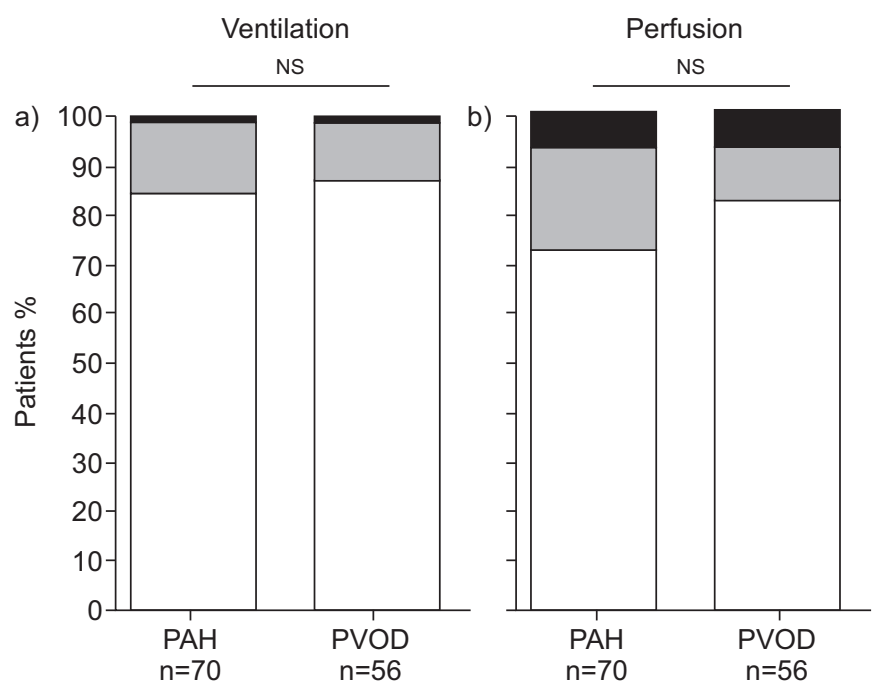

Segmental or subsegmental defects

Nonsystematised defects

Normal or nonsignificant abnormalities

FIGURE 1. Comparative evaluation of ventilation/perfusion lung scans between pulmonary arterial hypertension (PAH) and pulmonary veno-occlusive disease (PVOD) patients. a) Ventilation: normal or nonsignificant defects (84.3\% versus $85.7 \%$ patients; $p=0.97$ ); nonsystematised defects ( $14.3 \%$ versus $12.5 \%$ patients; $p=0.97)$; segmental or subsegmental defects $(1.4 \%$ versus $1.7 \% ; p=0.58)$. b) Perfusion: normal or nonsignificant defects ( $72.9 \%$ versus $82.1 \%$ patients; $p=0.30$ ); nonsystematised defects (20\% versus $10.7 \%$; $p=0.24$ ); segmental or subsegmental defects $(7.1 \%$ versus $7.1 \% ; p=0.72)$. NS: nonsignificant. 


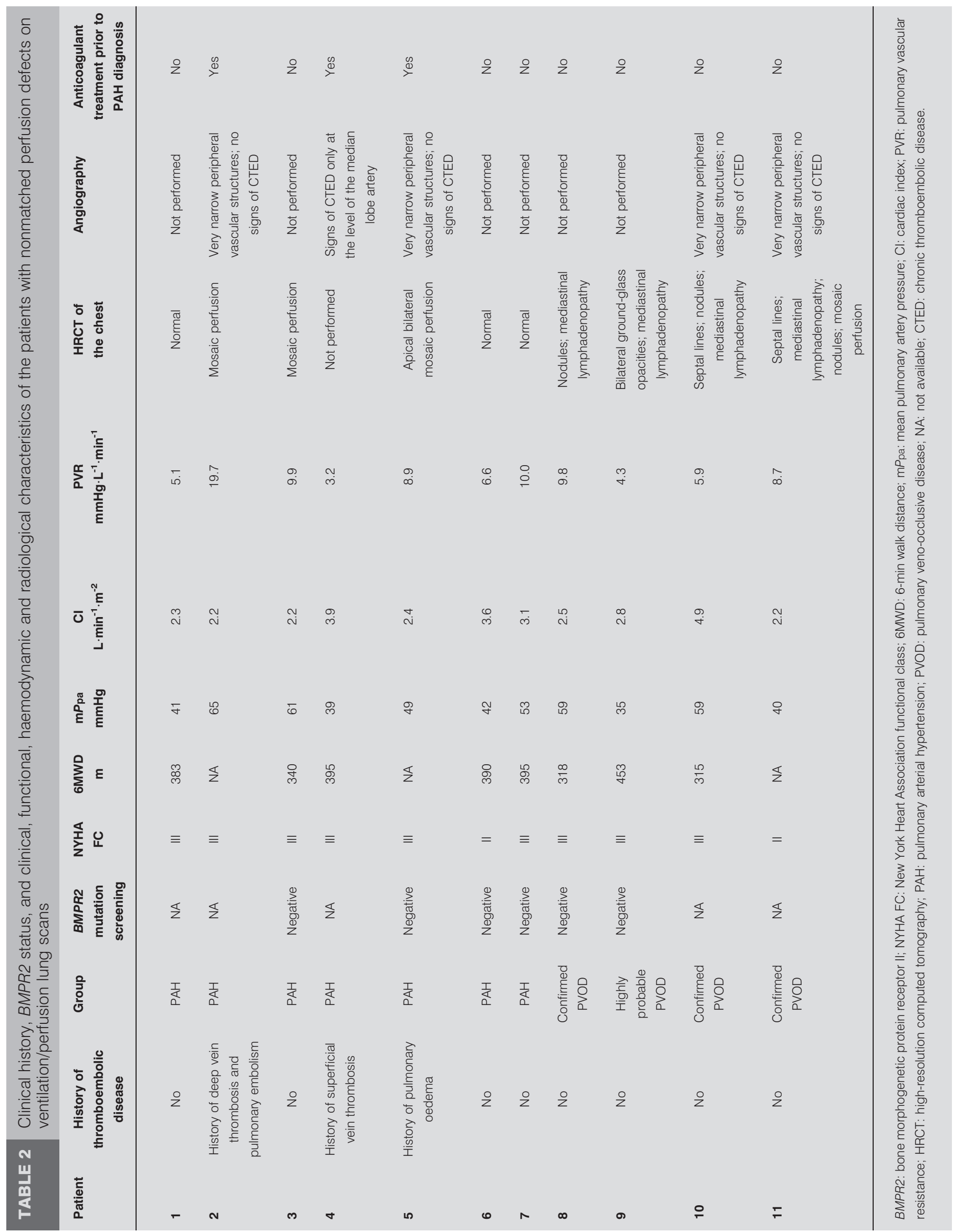


TABLE 3 Demographic, clinical, haemodynamic and functional characteristics of patients with nonmatched perfusion defects on ventilation/perfusion $\left(V^{\prime} / Q^{\prime}\right)$ lung scan versus patients with normal or matched perfusion defects

Nonmatched perfusion defects

Patients $n$

PAH/PVOD n (ratio)

Age at diagnosis yrs

Female/male n (ratio)

NYHA FC

II

III

IV

6MWD m

$\mathrm{mPpa} \mathrm{mmHg}$

CI L $\cdot \min ^{-1} \cdot \mathrm{m}^{-2}$

PVR $\mathrm{mmHg} \cdot \mathrm{L}^{-1} \cdot \mathrm{min}^{-1}$

$\mathrm{Sv}, \mathrm{O}_{2} \%$

$D \mathrm{~L}, \mathrm{CO} \%$ pred

BMPR2 status $\mathrm{n} / \mathrm{N} 0 \%$
11

$7 / 4(1.7)$

$42 \pm 20$

$8 / 3(2.6)$

$2(18.8)$

9 (81.2)

0

$271 \pm 178$

$49 \pm 10$

$2.93 \pm 0.8$

$8.3 \pm 4$

$63 \pm 9$

$51.7 \pm 28.6$

$0 / 6(0)$
Normal $V^{\prime} / Q^{\prime}$ lung scans or matched defects p-value

115

$63 / 52(1.21)$

$53 \pm 18$

$53 / 62(0.8)$

0.81

0.06

0.16

11 (9)

89 (78)

15 (13)

$264 \pm 169$

$52 \pm 13$

$2.51 \pm 0.8$

$12.1 \pm 8$

$61 \pm 10$

$46.9 \pm 24.8$

$4 / 66$ (6)
0.33

0.89

0.45

0.03

0.06

0.36

0.27

0.75

Data are presented as mean \pm SD or $n$ (\%), unless otherwise stated. PAH: pulmonary arterial hypertension; PVOD: pulmonary veno-Occlusive disease; NYHA FC: New York Heart Association functional class; 6MWD: 6-min walk distance; mPpa: mean pulmonary artery pressure; $\mathrm{Cl}$ : cardiac index; PVR: pulmonary vascular resistance; Sv, ${ }_{2}$ : mixed venous oxygen saturation; DL,CO: diffusing capacity of the lung for carbon monoxide; \% pred: \% predicted; BMPR2: bone morphogenetic protein receptor II.

significantly higher cardiac index in patients with nonmatched defects (mean \pm SD $2.93 \pm 0.84$ versus $2.51 \pm 0.84 \mathrm{~L} \cdot \mathrm{min}^{-1} \cdot \mathrm{m}^{-2}$; $\mathrm{p}=0.03)$.

\section{$\mathbf{V}^{\prime} / \mathbf{Q}^{\prime}$ lung scan analysis of patients with histologically confirmed PVOD}

In histologically confirmed PVOD patients $(n=12)$, eight $(66.6 \%)$ patients had a normal perfusion, two $(16.6 \%)$ had nonsystematised and two (16.6\%) had segmental or subsegmental defects. Regarding ventilation, nine $(75 \%)$ patients had a normal ventilation on $V^{\prime} / Q^{\prime}$ lung scanning, two $(16.6 \%)$ had nonsystematised ventilation defects and 1 (8.3\%) had segmental ventilation defects.

In figure 2, we present an illustrative case of a PVOD patient with HRCT highly suggestive of PVOD, histological proofs of PVOD and a normal $V^{\prime} / Q^{\prime}$ lung scan. Among the other histologically confirmed PVOD patients, only one (8.3\%) had a nonmatched segmental perfusion defect on $V^{\prime} / Q^{\prime}$ lung scan, and histological examination found venular and capillary involvement characteristic of PVOD associated with thrombotic lesions (fig. 3). In this selected case, HRCT of the chest showed typical PVOD findings including septal lines, centrilobular ground-glass opacities and mediastinal lymph node enlargement associated with mosaic perfusion. Pulmonary angiography revealed attenuation of peripheral pulmonary arteries without radiological signs of chronic thromboembolic disease.

\section{DISCUSSION}

PVOD is a rare and severe condition with a poor prognosis that requires an early diagnosis because of the need for specific management, including high-dose diuretics, careful management of specific PAH therapy and early referral for lung transplantation $[11,13,23,24]$. The main risk for these patients is the development of acute pulmonary oedema with the use of PAH-specific drugs (prostacyclin, prostacyclin analogues, endothelin receptor antagonists or phosphodiesterase- 5 inhibitors), which may promote fluid extravasation from the capillaries to the alveolus by acting mainly as arteriolar vasodilators against a venular obstruction due to specific remodelling $[8,12,13]$. The definitive diagnosis of PVOD requires histological examination of lung tissue samples. As lung biopsy is a high-risk procedure in the setting of $\mathrm{PAH}$, it is not recommended, and histological proof of PVOD is usually retrospectively obtained after death or lung transplantation [8, 11]. Therefore, a reliable noninvasive approach is needed for the diagnosis of PVOD. We recently demonstrated that HRCT of the chest showing septal lines, ground-glass opacities and lymph node enlargement, low $\mathrm{DL}, \mathrm{CO}$, and presence of intraalveolar haemorrhage on bronchoalveolar lavage may be helpful to discriminate patients with highly probable PVOD $[8,15,16]$.

The $V^{\prime} / Q^{\prime}$ lung scan is a relatively inexpensive and widely available investigation that is recommended in the management and diagnosis of pulmonary hypertension to screen for CTEPH because of its higher sensitivity than computed tomography $[4,5,25,26]$. A normal or low-probability $V^{\prime} / Q^{\prime}$ lung scan effectively excludes CTEPH with a high sensitivity and specificity [4,5]. Recent ERS/ESC guidelines also affirm that nonmatched perfusion is a caveat because these defects are also seen in PVOD, suggesting that $V^{\prime} / Q^{\prime}$ lung scanning may be helpful to screen PVOD patients $[4,5]$.

To our knowledge, this assertion in the recent ERS/ESC guidelines is based on a series of three cases of PVOD, where patients with high-probability $V^{\prime} / Q^{\prime}$ lung scans and negative 
a)
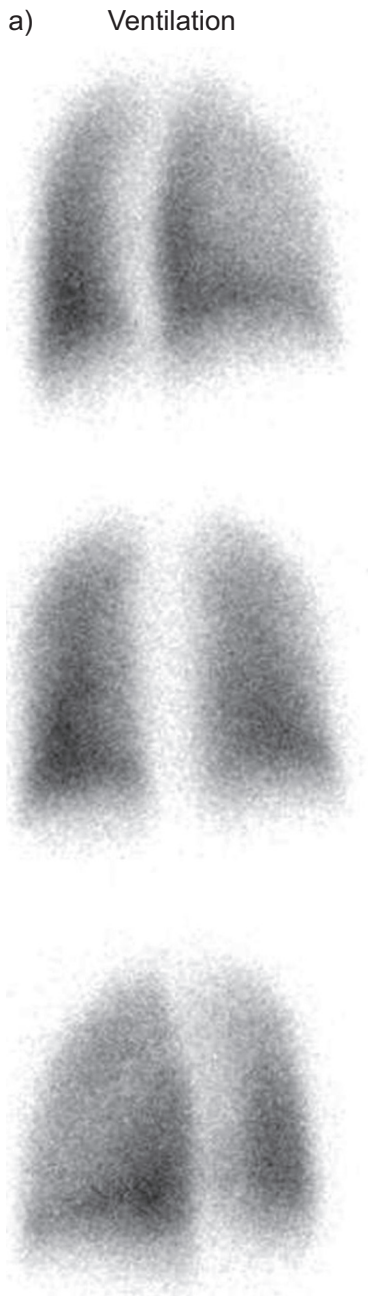

Perfusion

RPO
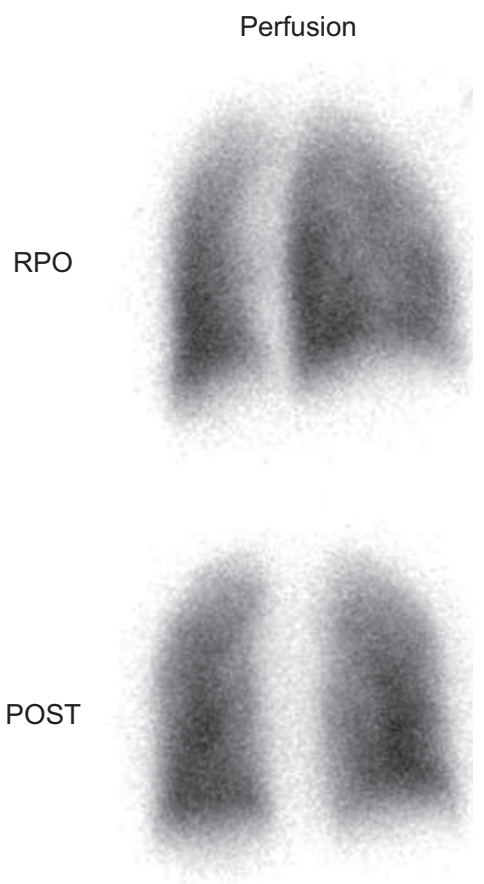

LPO
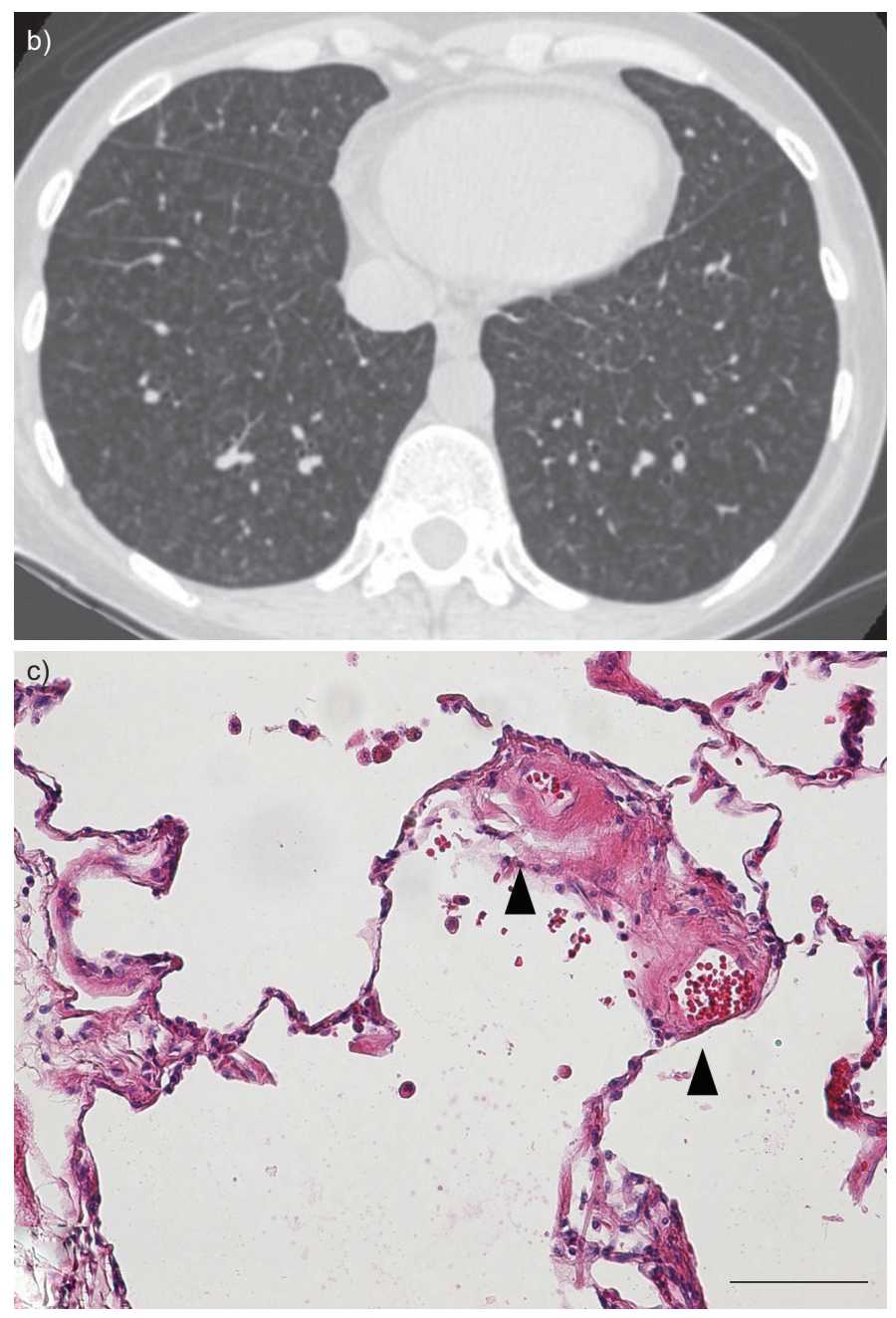

FIGURE 2. Review of a patient with confirmed pulmonary veno-occlusive disease (PVOD) and normal ventilation/perfusion ( $\left.V^{\prime} / Q^{\prime}\right)$ lung scan. a) $V^{\prime} / Q^{\prime}$ lung scan with normal ventilation and perfusion. b) High-resolution computed tomography with typical PVOD findings: septal lines and centrilobular ground-glass opacities. c) Histological sample. Arrowheads: pre-septal veins with intimal fibrosis. Haematoxylin-eosin-safran staining. LPO: left posterior oblique view; RPO: right posterior oblique view; POST: posterior view. Scale bar $=100 \mu \mathrm{m}$.

angiograms for arterial obstruction had a focal "downstream" process suggestive of PVOD at angiography, which was confirmed histologically in two of the cases [17].

The present study reviewed the $V^{\prime} / Q^{\prime}$ lung scans at time of diagnosis for confirmed or highly probable PVOD and idiopathic or heritable PAH patients. There was no difference in lung perfusion between PVOD and PAH patients, and the same proportion of segmental or subsegmental perfusion defects $(7.1 \%)$ was observed in both groups. Furthermore, there is a statistically nonsignificant trend toward a higher proportion of nonsystematised perfusion defects in $\mathrm{PAH}$ patients $(20 \%)$ than in PVOD patients $(10.8 \%)$ (online supplementary table). These perfusion abnormalities may be due to in situ thrombosis, which has been described in histological samples of idiopathic PAH [27-29]. Based on this observation, RICH et al. [30] demonstrated, in a period when no specific PAH therapy was available, that anticoagulation may improve survival of idiopathic PAH patients. Regarding ventilation, we have found no significant differences between the percentage of nonsystematised and segmental/subsegmental defects between PVOD and PAH. It has been clearly demonstrated that HRCT may discriminate PVOD patients among idiopathic PAH patients, by showing abnormalities suggestive of PVOD (septal lines, ground-glass opacities and lymph node enlargement) $[8,15]$. Therefore, it could be suspected that PVOD may be associated with more frequent abnormal ventilation on $V^{\prime}$ / $Q^{\prime}$ lung scans, as compared with PAH patients. However, our data confirmed that ventilation defects were not significantly associated with PVOD signs on HRCT. Interestingly, we present an illustrative case of a PVOD patient in figure 2 with a highly suggestive HRCT, a histological confirmation and a normal $V^{\prime} / Q^{\prime}$ lung scan. In conclusion, PAH and PVOD are two entities that do not influence per se the distribution of the radionuclide substance in ventilation, having both similar flow and volumes measured by pulmonary functional tests; however, an abnormal ventilation may signify an incorrect manoeuvre or the presence of other lung disease [7]. The rare association of nonmatched perfusion defects and the diagnosis of PVOD or idiopathic PAH suggest the absence of correlation 
a)
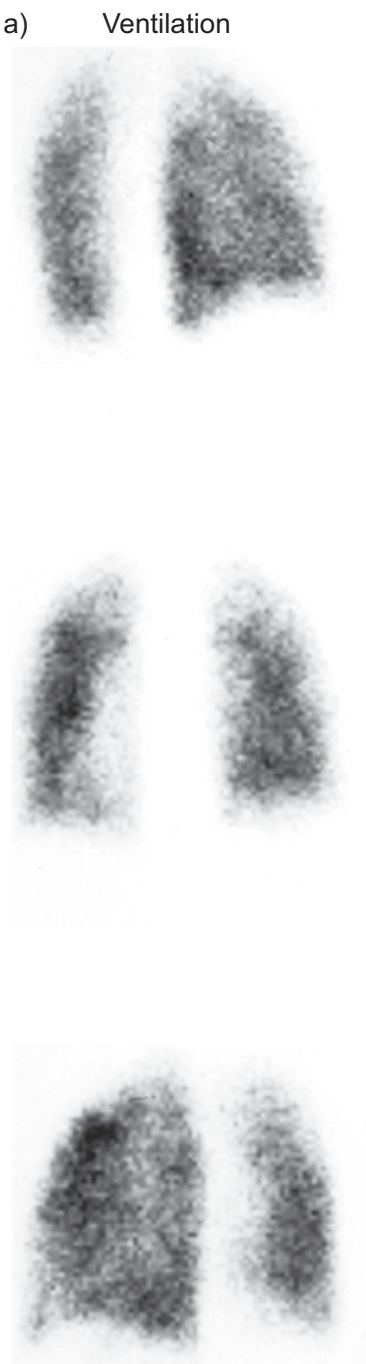

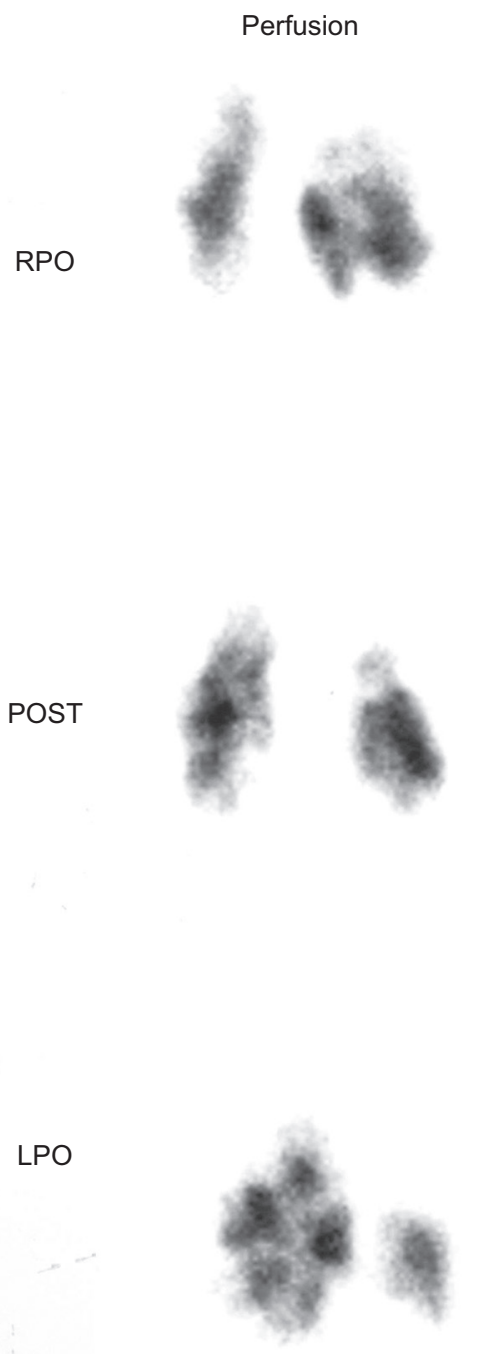

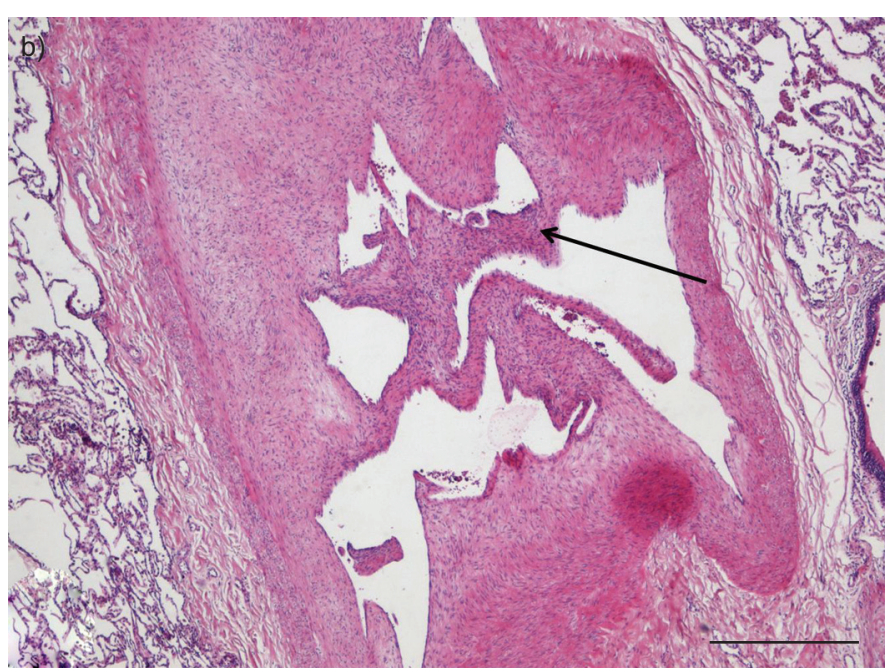

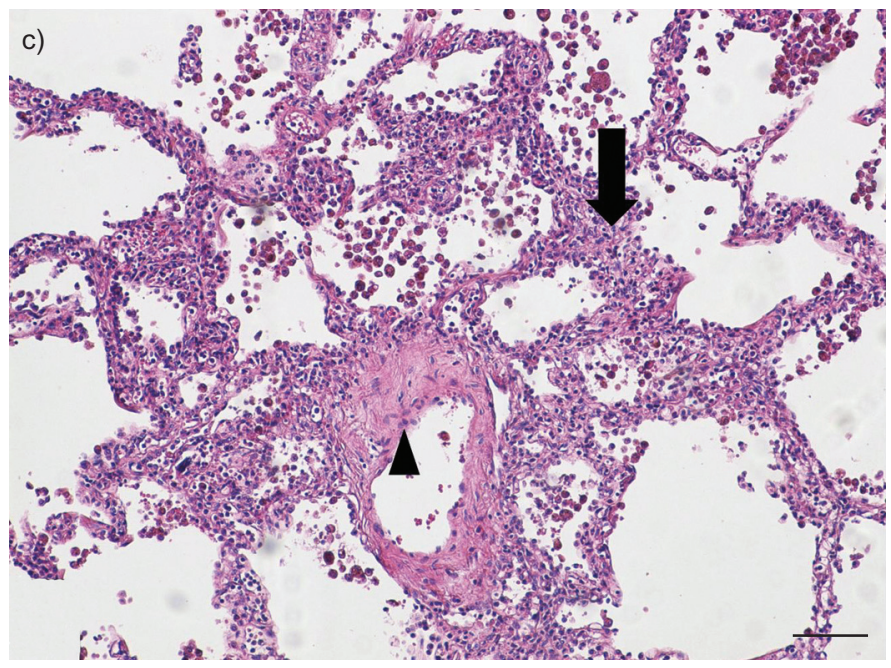

FIGURE 3. Review of a patient with confirmed pulmonary veno-occlusive disease and nonmatched perfusion defects. a) Ventilation/perfusion lung scan with multiple nonmatched perfusion defects: right superior lobe, right basal pyramid, culmen and left inferior lobe. b, c) Multiple histological samples from the same patient. Narrow arrow: repermeabilised old thrombus; arrowhead: fibrosed vein; wide arrow: focal lesion of pulmonary haemangiomatosis. Haematoxylin-eosin-safran staining. LPO: left posterior oblique view; RPO: right posterior oblique view; POST: posterior view. Scale bars: a) $500 \mu \mathrm{m}$; b) $100 \mu \mathrm{m}$.

between abnormal $V^{\prime} / Q^{\prime}$ lung scan and the diagnosis of PVOD, either confirmed histologically or highly probable.

In our study, we found 11 patients (seven PAH and four PVOD patients) with nonmatched perfusion defects. Three PAH patients had nonmatched perfusion defects and a history of thromboembolic events (two had a previous acute pulmonary embolism that required anticoagulation therapy and a third patient had a superficial vein thrombosis $>5$ yrs prior to $\mathrm{PAH}$ diagnosis), whereas none of the four PVOD patients had a history of thromboembolic events. We further analysed the clinical and haemodynamic data from these patients and found no statistically significant difference between them and the rest of the patients, with the exception of a higher mean cardiac index. This finding does not support the idea that more severe PAH patients have a greater risk of in situ thrombosis due to low cardiac index [31, 32]. However, our data suggest that no haemodynamic characteristics seem to be associated with perfusion scan abnormalities. Based on these results, it can therefore be suggested that low cardiac index was not a risk factor for in situ thrombosis in PAH or PVOD patients. In our cohort, BMPR2 mutation was observed only in three out of 72 PAH or PVOD patients tested, which does not allow us to conclude on the impact of $B M P R 2$ mutations on $V^{\prime} / Q^{\prime}$ lung scanning; however, these three PAH patients with BMPR2 mutations had no specific abnormalities. In particular, none of the six patients with nonmatched perfusion defects and genetic testing had BMPR2 mutations. In this context, it could be interesting to evaluate other characteristics, such as age, sex or deficiency of coagulation, in a large cohort of PAH patients to find predictive factors of in situ thrombosis in these patients and better understand the impact of anticoagulant in these disorders.

To our knowledge, no systematic analysis of $V^{\prime} / Q^{\prime}$ lung scans has already been performed in a cohort of PAH or PVOD patients of this size. European guidelines suggesting a role for $V^{\prime} / Q^{\prime}$ lung scanning in PVOD patients were based on the 
analysis of a selected report of three PVOD patients showing that nonmatched perfusion lung scans may not necessarily be associated with proximal CTEPH. These observations may be in accordance with our results, because in our cohort of wellcharacterised PVOD patients, we found four PVOD patients with nonmatched pulmonary defects in a period of $8 \mathrm{yrs}$. However, these abnormalities were not specific to PVOD and were observed in the same proportion in PAH patients. Of the three patients with nonmatched perfusion defects reported by BAILEY et al. [17], two had no history of thromboembolic events and PVOD diagnosis was confirmed by histology. The last case had a presumed diagnosis of pulmonary embolism made during pregnancy and was treated with oral anticoagulation therapy for 3 yrs before the diagnosis of pre-capillary pulmonary hypertension was made. HRCT in this patient showed features compatible with the diagnosis of PVOD and the diagnosis of PVOD was suggested by focal venous obstructions at venography. The authors hypothesised that the distribution of radionuclide particles during perfusion scanning may be altered by the high downstream resistance due to venular involvement, resulting in regional differences in pulmonary blood flow. Our analysis showed no clinical or haemodynamic difference between the PAH and PVOD patients with nonmatched perfusion defects, with, if anything, cardiac idn being higher in those with nonmatched $V^{\prime} / Q^{\prime}$ defects (table 3).

Our study is the first large-scale systematic analysis of $V^{\prime} / Q^{\prime}$ lung scans in a substantial cohort of PVOD patients. A limitation of our study was that only 12 PVOD patients had the diagnosis confirmed histologically, while in the rest, we used the established noninvasive diagnostic criteria. However, because of the rarity of PVOD and the contraindication of lung biopsy in these patients, the proportion of histologically confirmed PVOD in fact represents one of the most important series of those with a confirmed diagnosis. Another strength was that all patients that had nonmatched perfusion defects were further investigated by computed tomography scan and/or angiography in order to rule out the possibility of CTEPH. The low number of patients having a BMPR2 mutation could not give us information on a specific $V^{\prime} / Q^{\prime}$ pattern for this subgroup, although it cannot be excluded that such a status may be associated with nonmatched perfusion defects.

In conclusion, nonmatched perfusion defects on $V^{\prime} / Q^{\prime}$ lung scans are an uncommon observation in idiopathic or heritable PAH and PVOD patients, and $V^{\prime} / Q^{\prime}$ lung scanning may mimic CTEPH in the same proportion in both conditions. Even if PVOD is characterised by abnormalities on HRCT of the chest, abnormalities in ventilation lung scans are infrequent and observed in the same proportion in idiopathic PAH patients. Our data also suggest that nonmatched perfusion defects are not associated with more pronounced haemodynamic impairment and the hypothesis of in situ thrombosis induced by low cardiac output should be therefore reconsidered. According to our results, the role of $V^{\prime} / Q^{\prime}$ lung scans in the diagnostic algorithm for pulmonary hypertension should be modified in future guidelines: although $V^{\prime} / Q^{\prime}$ lung scanning remains essential for the screening of CTEPH patients, it may not be such a useful tool to discriminate PVOD.

\section{STATEMENT OF INTEREST}

Statements of interest for O. Sitbon, M. Humbert, G. Simonneau and D. Montani can be found at www.erj.ersjournals.com/site/misc/ statements.xhtml

\section{REFERENCES}

1 Rubin LJ. Primary pulmonary hypertension. N Engl J Med 1997; 336: 111-117.

2 Simonneau G, Robbins IM, Beghetti M, et al. Updated clinical classification of pulmonary hypertension. J Am Coll Cardiol 2009; 54: Suppl. 1, S43-S54.

3 Humbert M, Sitbon O, Simonneau G. Treatment of pulmonary arterial hypertension. N Engl J Med 2004; 351: 1425-1436.

4 Galie N, Hoeper MM, Humbert M, et al. Guidelines for the diagnosis and treatment of pulmonary hypertension. Eur Respir $J$ 2009; 34: 1219-1263.

5 Galie N, Hoeper MM, Humbert M, et al. Guidelines for the diagnosis and treatment of pulmonary hypertension: the Task Force for the Diagnosis and Treatment of Pulmonary Hypertension of the European Society of Cardiology (ESC) and the European Respiratory Society (ERS), endorsed by the International Society of Heart and Lung Transplantation (ISHLT). Eur Heart J 2009; 30: 2493-2537.

6 Holcomb BW Jr, Loyd JE, Ely EW, et al. Pulmonary veno-occlusive disease: a case series and new observations. Chest 2000; 118: 1671-1679.

7 Mandel J, Mark EJ, Hales CA. Pulmonary veno-occlusive disease. Am J Respir Crit Care Med 2000; 162: 1964-1973.

8 Montani D, Achouh L, Dorfmuller P, et al. Pulmonary venoocclusive disease: clinical, functional, radiologic, and hemodynamic characteristics and outcome of 24 cases confirmed by histology. Medicine (Baltimore) 2008; 87: 220-233.

9 Montani D, Achouh L, Sitbon O, et al. Pulmonary venoocclusive disease and failure of specific therapy. Chest 2009; 136: 1181.

10 Pietra GG, Capron F, Stewart S, et al. Pathologic assessment of vasculopathies in pulmonary hypertension. J Am Coll Cardiol 2004; 43: Suppl. 12, 25S-32S.

11 Montani D, Price LC, Dorfmuller P, et al. Pulmonary venoocclusive disease. Eur Respir J 2009; 33: 189-200.

12 Palmer SM, Robinson LJ, Wang A, et al. Massive pulmonary edema and death after prostacyclin infusion in a patient with pulmonary veno-occlusive disease. Chest 1998; 113: 237-240.

13 Montani D, Jais X, Price LC, et al. Cautious epoprostenol therapy is a safe bridge to lung transplantation in pulmonary veno-occlusive disease. Eur Respir J 2009; 34: 1348-1356.

14 Lantuejoul S, Sheppard MN, Corrin B, et al. Pulmonary venoocclusive disease and pulmonary capillary hemangiomatosis: a clinicopathologic study of 35 cases. Am J Surg Pathol 2006; 30: 850-857.

15 Resten A, Maitre S, Humbert M, et al. Pulmonary hypertension: CT of the chest in pulmonary venoocclusive disease. AJR Am J Roentgenol 2004; 183: 65-70.

16 Rabiller A, Jais X, Hamid A, et al. Occult alveolar haemorrhage in pulmonary veno-occlusive disease. Eur Respir J 2006; 27: 108-113.

17 Bailey CL, Channick RN, Auger WR, et al. "High probability" perfusion lung scans in pulmonary venoocclusive disease. Am J Respir Crit Care Med 2000; 162: 1974-1978.

18 Chazova I, Robbins I, Loyd J, et al. Venous and arterial changes in pulmonary veno-occlusive disease, mitral stenosis and fibrosing mediastinitis. Eur Respir J 2000; 15: 116-122.

19 Dorfmuller P, Humbert M, Perros F, et al. Fibrous remodeling of the pulmonary venous system in pulmonary arterial hypertension associated with connective tissue diseases. Hum Pathol 2007; 38: 893-902. 
20 Girerd B, Montani D, Coulet F, et al. Clinical outcomes of pulmonary arterial hypertension in patients carrying an ACVRL1 (ALK1) mutation. Am J Respir Crit Care Med 2010; 181: 851-861.

21 Sitbon $\mathrm{O}$, Humbert M, Jais X, et al. Long-term response to calcium channel blockers in idiopathic pulmonary arterial hypertension. Circulation 2005; 111: 3105-3111.

22 ATS Committee on Proficiency Standards for Clinical Pulmonary Function Laboratories. ATS statement: guidelines for the sixminute walk test. Am J Respir Crit Care Med 2002; 166: 111-117.

23 Montani D, O'Callaghan DS, Savale L, et al. Pulmonary venoocclusive disease: recent progress and current challenges. Respir Med 2010; 104: Suppl. 1, S23-S32.

24 Montani D, Kemp K, Dorfmuller P, et al. Idiopathic pulmonary arterial hypertension and pulmonary veno-occlusive disease: similarities and differences. Semin Respir Crit Care Med 2009; 30: 411-420.

25 Tunariu N, Gibbs SJ, Win Z, et al. Ventilation-perfusion scintigraphy is more sensitive than multidetector CTPA in detecting chronic thromboembolic pulmonary disease as a treatable cause of pulmonary hypertension. J Nucl Med 2007; 48: 680-684.
26 Murray T, Hilditch TE, Bolster AA, et al. Perfusion lung scanning in pulmonary hypertension. Nucl Med Commun 1995; 16: 621-622.

27 Moser KM, Fedullo PF, Finkbeiner WE, et al. Do patients with primary pulmonary hypertension develop extensive central thrombi? Circulation 1995; 91: 741-745.

28 Egermayer P, Peacock AJ. Is pulmonary embolism a common cause of chronic pulmonary hypertension? Limitations of the embolic hypothesis. Eur Respir J 2000; 15: 440-448.

29 Rich S, Kaufmann E, Levy PS. The effect of high doses of calciumchannel blockers on survival in primary pulmonary hypertension. N Engl J Med 1992; 327: 76-81.

30 Rich S, Pietra GG, Kieras K, et al. Primary pulmonary hypertension: radiographic and scintigraphic patterns of histologic subtypes. Ann Intern Med 1986; 105: 499-502.

31 Kawut SM, Horn EM, Berekashvili KK, et al. New predictors of outcome in idiopathic pulmonary arterial hypertension. Am J Cardiol 2005; 95: 199-203.

32 Rubenfire M, Bayram M, Hector-Word Z. Pulmonary hypertension in the critical care setting: classification, pathophysiology, diagnosis, and management. Crit Care Clin 2007; 23: 801-834. 